\title{
Influence of roasting olive fruit on the chemical composition and polycyclic aromatic hydrocarbon content of olive oil
}

\author{
Said Gharby ${ }^{1,2}$, Hicham Harhar ${ }^{2, *}$, Mustapha Farssi ${ }^{1,3}$, Abdelaziz Ait Taleb ${ }^{1}$, Dominique Guillaume ${ }^{4}$ \\ and Abdellatif Laknifli ${ }^{1}$ \\ ${ }^{1}$ Laboratoire de Physicochimie des Milieux Naturels et Matériaux Bioactifs, Faculté Polydisciplinaire de Taroudant, Université Ibn Zohr, \\ Taroudant, Maroc \\ ${ }^{2}$ Laboratoire de Chimie des Plantes et de Synthèse Organique et Bioorganique, Faculté des Sciences, Université Mohammed V-Agdal, \\ BP 1014 Rabat, Maroc \\ ${ }^{3}$ Laboratoire de contrôle qualité, CIBELII, Agadir, Maroc \\ ${ }^{4}$ CNRS-UMR7312, UFR Med-Pharm., Chimie Thérapeutique, Reims, France
}

Received 25 September 2017 - Accepted 19 February 2018

\begin{abstract}
Alwana olive oil is a special product of the people from the mountains of Morocco. To produce this oil, prior to the pressing procedure, olives are roasted at up to $130^{\circ} \mathrm{C}$, which leads to the formation of a typical roasty and nutty aroma. It can be expected that this process, which strongly differs from the usual production technic of virgin olive oil, impact the oil chemical composition. We observed that the roasting process has no influence on the fatty acid and sterol composition of Alwana olive. Concentration in $\alpha$-tocopherol underwent a slight decrease (from 93 to $91 \%$ ) whereas $\gamma$-tocopherol, polyphenol, and chlorophyll content were increased by the roasting process. Polycyclic aromatic hydrocarbon content was found to be $50 \mu \mathrm{g} \mathrm{kg}^{-1}$.
\end{abstract}

Keywords: oil / Alwana olive / roasting / oxidative stability / polycyclic aromatic hydrocarbons

Résumé - Influence de la torréfaction des olives sur la composition chimique et la teneur en hydrocarbures aromatiques polycycliques de l'huile d'olive. L'huile d'olive Alwana est un produit spécial préparé par les habitants des montagnes du Maroc. Pour la production de cette huile, avant la procédure de pressage, les olives sont torréfiées à des températures allant jusqu'à $130^{\circ} \mathrm{C}$, ce qui conduit à la formation de l'arôme typique de fumé et de noisette. Dans cette étude, aucun changement de la composition des acides gras et des stérols au cours du processus de torréfaction n'a été observé. Les concentrations en $\alpha$-tocophérol ont légèrement diminué de 93 à $91 \%$. Par contre, les taux de $\gamma$-tocophérol, de polyphénols et de chlorophylle sont augmentés pendant la torréfaction. La teneur en hydrocarbures aromatiques polycycliques atteint $50 \mu \mathrm{g} \mathrm{kg}^{-1}$.

Mots clés : huile / huile d'olive Alwana / torréfaction / stabilité oxydative / hydrocarbures polycycliques aromatiques

\section{Introduction}

The fruit of the Olive tree (Olea europaea L.) is undoubtedly one of the most important and typical fruit throughout the Mediterranean Basin (Mataix et al., 2008). Olive oil, derived from the oily juice of the olive, is considered as a health food, especially when consumed under its crude form, thus preserving fatty acids, vitamins and phenolic compounds of nutritional importance (Stark and Madar, 2002).

*Corresponding author: hichamoo79@yahoo.fr
Olive oil fatty acid composition is characterized by a good balance between saturated, monounsaturated, and polyunsaturated acids. Besides, olive oil has been recommended and used since ancient times for the prevention of cardiovascular diseases and for its anti-oxidative capacity (Allalout et al., 2009; Djebali et al., 2012).

Generally speaking, the ideal objective of any oil production method is to extract the largest possible amount of oil without altering its original quality (Gharby et al., 2013). However, to ascertain olive oil quality, the Codex Alimentarius, the international olive council (IOC), and EC regulations consider virgin olive oil as being "the oil obtained from the 


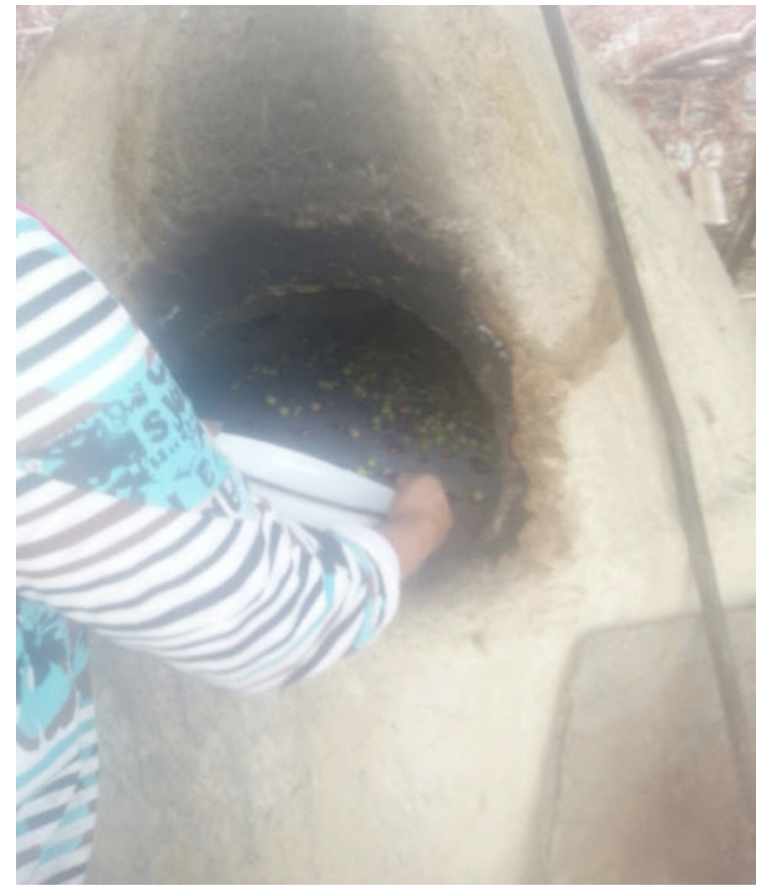

Fig. 1. Women put Fresh ripe olives in a closed oven.

fruit of the olive tree solely by mechanical or other physical means under conditions that do not lead to alteration in the oil, excluding other treatment than washing, decantation, centrifugation, or filtration. This excludes using solvents or using adjuvants having a chemical or biochemical action". However, in Morocco there is know-how to produce a different olive oil called "Alwana oil" (AO). Characteristic of some Moroccan regions, $\mathrm{AO}$ is the culmination of a procedure of four consecutive stages following the harvest of the olives: roasting in a hot oven (kiln), grinding, kneading and pressing the fruit. The process has some similarities with the Millennium extraction process of argan oil (El Alaoui, 2007).

In detail, the traditional preparative procedure of $\mathrm{AO}$ is performed as follows. Fresh ripe olives (generally $5 \mathrm{~kg}$ ) handpicked by women are spread out carefully in a closed oven overnight (about twelve hours) most often beforehand used for cooking traditional bread (Fig. 1). After this heating period, the dehydrated-dark colored-olives are rapidly placed in a clay bowl and women crushed the still hot olives between two stones (Fig. 2). The resulting coarse paste, consisting of pulp and olive debris, is called olive paste. These 2 steps take at least 90 minutes.

Then, the olive paste is heated in a clay bowl on a brazier powered by oak charcoal before to be kneaded while adding a small volume of hot water. At the end, the olive paste is introduced into round baskets, called scourtins, letting out the liquid while retaining the pulp and pits. To extract the maximum of oil, the baskets loaded with this paste (one or two) are placed on the lower plate of the bin of the press. By manual and progressive tightening of the press-nuts, the pressure plate is lowered onto the baskets. The press is then inclined against a wall until all oil is collected without human intervention. About $75 \mathrm{~mL}$ of oil can be extracted from $5 \mathrm{~kg}$ of fresh olives (El Alaoui, 2007).

To the best of our knowledge, chemical quality of Moroccan AO has only been shallowly studied, especially

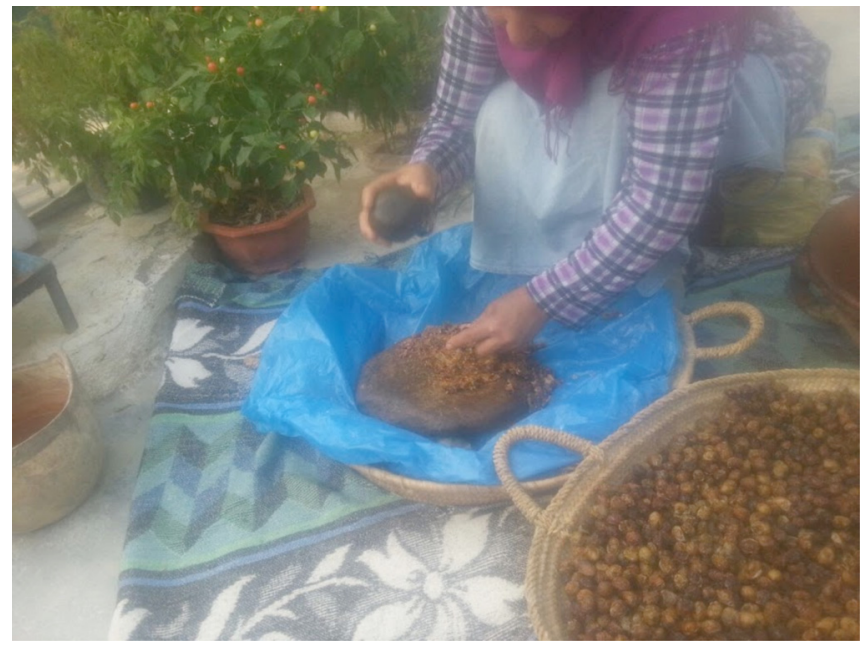

Fig. 2. Women crushed the still hot olives between two stones.

its oxidative stability. The objective of this study was to identify the impact of olive roasting on AO:

- fatty acid, sterol, polyphenol, and tocopherol composition;

- oxidative stability by the Rancimat test;

- polycyclic aromatic hydrocarbon content.

\section{Materials and methods}

\subsection{Olive sample preparation}

Greenish olive fruit (Picholine, $10 \mathrm{~kg}$ ) was harvested near Taounate, a city located in northern Morocco, $67 \mathrm{~km}$ in the north from Fes. Roasting was performed in a traditional oven at a temperature not exceeding $130^{\circ} \mathrm{C}$ for 12 hours. Roasted olives were crushed using two stones. Crushed olives were placed in a clay container which was set on fire and then the olives were further crushed by hand. Small amounts $(500 \mathrm{~mL})$ of hot water were then added gradually until obtaining a paste that was poured into a traditional sieve made of weaved palm tree, and pressed for 3 hours using a traditional press. From $10 \mathrm{~kg}$ of fruit, $1.4 \mathrm{~L}$ of $\mathrm{AO}$ were collected.

\subsection{Chemicals reagents}

All the reagents were of analytical or HPLC grade. 2,2,4trimethylpentane, heptane and isopropanol used in chromatography and cyclohexane used for extinction coefficient determination were purchased from Professional Labo (Casablanca, Morocco).

\subsection{Analytical determination}

All analytical determination was performed in triplicate and results are expressed as mean value and standard deviation.

\subsubsection{Physical and chemical oil parameters}

Free fatty acid content (FFA), peroxide value (PV), extinction coefficients $\left(K_{232}\right.$ and $\left.K_{270}\right)$, refractive index, and iodine value were determined according to European 
Commission Regulation EEC/2568/91 (2003). FFA content was expressed as weight percent of oleic acid. PV was expressed as Meq of active oxygen per kilogram of oil (Meq $\mathrm{O}_{2} / \mathrm{kg}$ oil), and extinction coefficients as the specific extinction of a $1 \%(\mathrm{w} / \mathrm{v})$ solution of oil in cyclohexane in a $1 \mathrm{~cm}$ cell path length, using a CARY 100 Varian UV spectrometer. Carotenoid and chlorophyll compounds were determined in cyclohexane at 470 and $670 \mathrm{~nm}$, respectively, using the specific extinction coefficients, according to the method of Mínguez-Mosquera et al. (1991). The values of specific extinction coefficients (E0) were 613 for pheophytin as major component in the chlorophyll fraction and 2000 for lutein as major component in the carotenoid fraction. Pigment contents were calculated as follows:

[Chlorophylls] mg kg-1A670* 106/613*100*d

[Carotenoids] mg kg-1A470*106/2000*100*d

Where $\mathrm{A}$ is the absorbance and $\mathrm{d}$ is the spectrophotometer cell thickness $(1 \mathrm{~cm})$. Chlorophyll and carotenoid contents were expressed as mg of pheophytin "a" and lutein per kg of oil, respectively.

\subsubsection{Fatty acid composition}

Before analysis, lipids containing fatty acids (FAs) were converted to fatty acid methyl esters (FAMEs) by shaking for $25 \mathrm{~min}$ a solution of $60 \mathrm{mg}$ oil and $3 \mathrm{~mL}$ of hexane with $0.3 \mathrm{~mL}$ of $2 \mathrm{~N}$ methanolic potassium hydroxide. FAMEs were analyzed by gas chromatography using a Varian CP-3800 (Varian Inc.) chromatograph equipped with a FID and a CP-Wax 52CB column $(30 \mathrm{~m} \times 0.25 \mathrm{~mm}$ id.; Varian Inc., Middelburg, The Netherlands). The carrier gas was helium and the flow rate was $1 \mathrm{~mL} / \mathrm{min}$. The initial and final column temperatures were $170^{\circ} \mathrm{C}$ and $230^{\circ} \mathrm{C}$, respectively, and the temperature was increased at a rate of $4^{\circ} \mathrm{C} / \mathrm{min}$. The injector and detector temperature was $230^{\circ} \mathrm{C}$. Data were processed using a Varian Star Workstation v 6.30 (Varian Inc., Walnut Creek, CA, USA). Results were expressed as the relative percentage of each individual FA present in the sample. Iodine value (IV) was computed from FAME percentages using the formula: $\mathrm{IV}=(\%$ palmitoleic $\times 1.001)+(\%$ oleic $\times 0.899)+(\%$ linoleic $\times 1.814)+(\%$ linolenic $\times 2.737)$.

\subsubsection{Sterol composition}

After isolation from the thin layer chromatography plate, the sterol fraction was prepared by trimethylsilylation according to the standard EN ISO 6799. Sterol composition was determined by gas chromatography using a Varian 3800 instrument equipped with a VF-1 ms column $(30 \mathrm{~m} \& 0.25 \mathrm{~mm}$ $i d$.) and using helium (flow rate $1.6 \mathrm{~mL} / \mathrm{min}$ ) as carrier gas. Column temperature was isothermal at $270^{\circ} \mathrm{C}$, injector and detector temperature was $300^{\circ} \mathrm{C}$. Injected volume was $1 \mu \mathrm{L}$. Data were processed using Varian Star Workstation v 6.30 (Varian Inc., Walnut Creek, CA, USA).

\subsubsection{Tocopherol composition}

For the analysis of the tocopherol content, high performance liquid chromatography (HPLC) was used, using a solution of $250 \mathrm{mg}$ of oil in $25 \mathrm{~mL}$ of $\mathrm{n}$-heptane. Tocopherols were analyzed by HPLC using Shimadzu CR8A instrument (Champ sur Marne, France) equipped with a C18 column $(25 \mathrm{~cm} \times 4 \mathrm{~mm}$; Varian
Inc., Middelburg, The Netherlands). Detection was performed using a fluorescence detector (excitation wavelength $290 \mathrm{~nm}$, detection wavelength $330 \mathrm{~nm}$ ). Eluent was a 99:1 isooctane/ isopropanol (v/v) mixture (flow rate $1.2 \mathrm{~mL} / \mathrm{min}$ ).

\subsubsection{Colorimetric determination of polyphenols}

Phenolic compounds were isolated by triple extraction of a solution of oil in hexane with a water/methanol mixture $(60: 40$, $\mathrm{v} / \mathrm{v})$. Total phenols were determined by adding the FolinCiocalteu reagent to a suitable aliquot of the combined extracts, and measuring the absorbance at $725 \mathrm{~nm} 2 \mathrm{~h}$ later using a spectrophotometer (Model Cary 100 Varian UV).

\subsubsection{Benzo[a]pyrene content}

Benzo[a]pyrene (B[a]P) content was determined following NF EN ISO 15302:2007 standard. Briefly, $2 \mathrm{~g}$ of oil were weighed (precision of $0.1 \mathrm{mg}$ ), then dissolved in petroleum ether (total volume $10 \mathrm{~mL}$ ). The mixture was homogenized by manual shaking. In a glass column $(300 \mathrm{~mm} \times 15 \mathrm{~mm})$ fitted with a sintered-glass filter, $22 \mathrm{~g}$ of aluminum oxide were introduced and topped with anhydrous sodium sulfate $(30 \mathrm{~mm})$ and the column was tapped to pack it. After conditioning the column by passing $30 \mathrm{~mL}$ of petroleum ether without allowing it to dry, $2 \mathrm{~mL}$ of oil solution were charged on the top of the column, and then eluted with an additional $5 \mathrm{~mL}$ of petroleum ether. The initial eluted fraction $(20 \mathrm{~mL})$ was discarded. The column was then eluted with additional petroleum ether and a $60 \mathrm{~mL}$ fraction was collected in a $100-\mathrm{mL}$ conical flask. The solvent was evaporated at $35^{\circ} \mathrm{C}$ under reduced pressure to approximately $0.50 \mathrm{~mL}$ and then dried under a nitrogen flow. For HPLC analysis, the residue was dissolved in $50 \mu \mathrm{L}$ of acetonitrile by shaking. An aliquot of $10 \mu \mathrm{L}$ was injected into the HPLC using an auto-sampler (ProStar 410, Varian Inc., and Walnut Creek, USA) with pick-up injection mode to avoid cross-contamination. HPLC system used was ProStar HPLC equipped with a Varian C18 column $(2 \mathrm{~cm} \times 4.6 \mathrm{~mm})$, and a ChromSep guard cartridge (Varian Chrompack, Varian Inc., Middelburg, The Netherlands). The column temperature was set at $20^{\circ} \mathrm{C}$ and a mixture of acetonitrile/water $(7: 1)$ was used as mobile phase at a flow rate of $1.2 \mathrm{~mL} / \mathrm{min}$. A Varian ProStar 363 fluorimetric detector was used with fluorescence emission at $306 \mathrm{~nm}$ and $408 \mathrm{~nm}$, data were processed using Varian Star Workstation v 6.30 (Varian Inc., Walnut Creek, USA).

\subsubsection{Oxidative stability}

The oxidative stability was evaluated by the Rancimat method. Stability was expressed as the oxidative induction period (IP, hours) measured at $110^{\circ} \mathrm{C}$ on a Rancimat 743 (Metrohm Co, Basel) apparatus using $3 \mathrm{~g}$ of oil sample with an air flow of $20 \mathrm{~L} / \mathrm{h}$. Volatile oxidation products were stripped from the oil and dissolved in cold water, whose conductivity increased progressively. The time taken to reach a level of conductivity was measured.

\section{Results and discussion}

To evaluate the impact of olive roasting, we decided to analyze $\mathrm{AO}$ and olive oil prepared from the same batch of fruit without roasting them. 
Table 1. Quality parameters of the olive oils.

\begin{tabular}{lccl}
\hline & Olive oil & Alwana & $\begin{array}{l}\text { Standard } \\
\text { (IOC) }\end{array}$ \\
\hline Moisture content (\%) & $0.18 \pm 0.02$ & $0.08 \pm 0.02$ & - \\
Free Fatty acid (\%) & $0.18 \pm 0.01$ & $0.21 \pm 0.02$ & $<0.8$ \\
Peroxid value meq O2/kg & $2.5 \pm 0.2$ & $0.8 \pm 0.2$ & $<20$ \\
K270 & $0.17 \pm 0.1$ & $0.32 \pm 0.1$ & $<0.20$ \\
K232 & $1.94 \pm 0.1$ & $1.79 \pm 0.1$ & $<2.5$ \\
Rancimat (h) & $26 \pm 2$ & $34 \pm 1.5$ & - \\
\hline
\end{tabular}

All values are the mean of three replicates \pm standard deviation of the mean.

\subsection{Effect of roasting of olive fruit on physicochemical characterization of olive oil}

Roasting of olives resulted in a significantly lower moisture content in AO compared to oil obtained from unroasted olives through the same preparation procedure (0.08\% vs. $0.18 \%$, Tab. 1$)$.

The FFA content, here referred as "acidity", is an important quality parameter used for classifying olive oil within a range commercial grades (COI, 2013). The higher percentage limit has been established internationally at $0.8 \%$ for FFAs (as oleic acid) in extra-virgin olive oil. Oils extracted from fresh healthy fruits and crushed according to best practices present a very low acidity (Gutierrez et al., 2000; Gharby et al., 2013). The acidity of the $\mathrm{AO}$ and olive oil from unroasted olive fruits was $0.18 \pm 0.01$ and $0.21 \pm 0.02 \%$, respectively (Tab. 1). Although both oils displayed acidity much lower than the allowed limit for extra virgin olive oil $(0.8 \%$; COI, 2013), our results show that roasting slightly increases the global acidity (Tab. 1). This likely results from easy known heat-induced hydrolysis of the triglycerides (Cossignani et al., 1998). This is also consistent with our observations on argan oil (Harhar et al., 2011) and those of Yoshida et al. on sunflower oil (2002), peanut and sesame oils (Yoshida et al., 1995, 2003; Fukuda, 1990). In all cases, FFA content increased with roasting time.

Peroxide value (PV) evaluates the hydroperoxide content and provides a measure of lipid oxidation. The PV of our reference olive oil was found to be $2.8 \mathrm{Meq} \mathrm{O}_{2} / \mathrm{kg}$ of oil whereas AO displayed a lower value $\left(0.8 \mathrm{meq} \mathrm{O}_{2} / \mathrm{kg}\right.$ of oil $)$ (Tab. 1). Therefore, heating of the olives in the oven may result in the accelerated degradation of hydroperoxides leading to a lower PV because of the formation of secondary oxidation products.

For the further evaluation of the influence of the roasting process on the oxidative stability, the specific extinction at 232 and $270 \mathrm{~nm}$ was determined immediately for the oil from roasted and unroasted olive fruits (Tab. 1). UV absorption at $232 \mathrm{~nm}\left(K_{232}\right)$ is useful to evaluate the presence of primary oxidation products. $K_{232}$ of $\mathrm{AO}$ was found to be lower than that of regular olive oil (Tab. 1). This can be explained by the formation of secondary oxidation products. Indeed, UV absorption at $270 \mathrm{~nm}\left(\mathrm{~K}_{270}\right)$, which is one of the markers used to monitor secondary oxidation products, was found to be twice higher in AO compared to olive oil (Tab. 1). Such high
Table 2. Fatty acid composition of different olive oils (\%).

\begin{tabular}{lccl}
\hline & Olive Oil & \multicolumn{1}{l}{ Alwana } & Standard \\
\hline Palmitic Acid C 16:0 & $10.3 \pm 0.57$ & $11.01 \pm 1.41$ & $7.50-20.00$ \\
Palmitoleic Acid C 16:1 & $0.54 \pm 0.05$ & $0.53 \pm 0.04$ & $0.30-3.50$ \\
Stearic Acid C 18:0 & $2.56 \pm 0.06$ & $2.35 \pm 0.21$ & $0.50-5.00$ \\
Oleic Acid C 18:1 & $75.2 \pm 0.98$ & $75.35 \pm 2.75$ & $55-83.00$ \\
Linoleic Acid C 18:2 & $9.21 \pm 0.55$ & $8.85 \pm 1.06$ & $3.50-21.00$ \\
Linolenic Acid C 18:3 & $0.9 \pm 0.02$ & $0.77 \pm 0.03$ & $<1.00$ \\
Arachidic Acid C 20:0 & $0.3 \pm 0.01$ & $0.33 \pm 0.01$ & $<0.60$ \\
Gadoleic Acid C 20:1 & $0.29 \pm 0.01$ & $0.28 \pm 0.02$ & $<0.40$ \\
SFA & 13.16 & 13.69 & \\
UFA & 86.14 & 85.78 & \\
\hline
\end{tabular}

All values are the mean of three replicates \pm standard deviation of the mean.

value signs the formation of secondary oxidation products, and is consistent with the low PV and reduced $\mathrm{K}_{232}$ absorption.

We evaluated the oxidative stability of AO using the Rancimat method at $110^{\circ} \mathrm{C}$. Olive oil prepared by pressing unroasted fruits presented an induction time of $26 \mathrm{~h}$, while AO had an induction time of $34 \mathrm{~h}$. These data confirm the transfer of Maillard reaction products developed during the roasting process into the olive oil and their preservative properties against oxidation (Morales and Babbel, 2002).

\subsection{Effect of roasting of olive fruits on fatty acid composition}

Fatty acid (FA) composition is an essential indicator for the nutritional value of the oil. Almost no significant differences were observed between the fatty acid composition of olive oils prepared with and without roasting of the olives before pressing (Tab. 2). Olive oil from unroasted olives contained the following acids; $10.3 \pm 0.57 \%$ palmitic, $2.56 \pm 0.06 \%$ stearic, $75.2 \pm 0.98 \%$ oleic, and $9.21 \pm 0.55 \%$ linoleic acids. AO consisted of $11.0 \pm 1.41 \%$ palmitic, $2.35 \pm 0.21 \%$ stearic, $75.3 \pm 2.75 \%$ oleic, and $8.85 \pm 1.06 \%$ linoleic acids. Lack of influence of roasting parameters on FA composition is not surprising and has already been reported for other oils (Lee et al., 2004, Anjum et al., 2006). Our results confirm the good stability of olive oil fatty acids.

\subsection{Effect of roasting of olive fruits on sterol composition of olive oil}

Sterols are also important constituents of olive oils because they relate to the quality of the oil and are widely used to check authenticity. Sterol composition of the oils is reported in Table 3. Both olive oil samples analyzed showed high $\beta$-sitosterol content. Olive oil is known to be particularly rich in $\beta$-sitosterol (Gharby et al., 2012). This high content is likely to be responsible of olive oil excellent preservation properties as well as of most of its physiological properties (Moreau et al., 2002). In the present study, similar sterol levels were determined for olive oil prepared from roasted or unroasted 
Table 3. Sterol composition of different olive oils (\%).

\begin{tabular}{llrl}
\hline & Olive oil & \multicolumn{1}{c}{ Alwana } & Standard \\
\hline Campesterol & $2.75 \pm 0.1$ & $2.7 \pm 0.1$ & $<4.0$ \\
Stigmasterol & $0.95 \pm 0.1$ & $1.1 \pm 0.1$ & $<$ Campesterol \\
$\beta$-Sitosterol & $88.9 \pm 0.7$ & $88.55 \pm 0.1$ & $>93$ \\
$\Delta$ 5-Avenosterol & $5.45 \pm 0.5$ & $5.7 \pm 0.4$ & \\
$\Delta$ 7-Stigmasterol & $0.25 \pm 0.1$ & $0.15 \pm 0.1$ & $<0.5$ \\
$\Delta$ 7-Avenosterol & $0.25 \pm 0.1$ & $0.2 \pm 0.1$ &
\end{tabular}

All values are the mean of three replicates \pm standard deviation of the mean.

Table 4. Natural antioxidant content of olive oils.

\begin{tabular}{lcc}
\hline & Olive oil & Alwana \\
\hline$\alpha$-tocopherol & $93.72 \pm 4$ & $91.70 \pm 5$ \\
$\gamma$-tocopherol & $2.81 \pm 0.3$ & $4.50 \pm 0.5$ \\
$\delta$-tocopherol & $3.47 \pm 0.2$ & $3.78 \pm 0.2$ \\
Polyphenols & $226 \pm 5.5$ & $293 \pm 5.5$ \\
$\beta$-Carotene $(\mathrm{mg} / \mathrm{kg})$ & $4.96 \pm 0.1$ & $7.11 \pm 0.2$ \\
Chlorophyll $(\mathrm{mg} / \mathrm{kg})$ & $9.1 \pm 2.3$ & $24.1 \pm 2.4$ \\
\hline
\end{tabular}

All values are the mean of three replicates \pm standard deviation of the mean.

fruit (Tab. 3). Even after roasting, $\beta$-sitosterol content in olive oil was found to be very high (Tab. 3 ). $\Delta 5$-avenastenol is known to act as an antioxidant and antipolymerization agent in frying oils (Giocametti and Milin, 2001, Gordon and Magos, 1983). During roasting, nor $\Delta 5$-avenasterol neither campesterol and stigmasterol changed significantly. The results show that the sterol content of olive oil was not sensitive to fruit roasting.

\subsection{Effect of roasting of olive fruits on natural antioxidants contents of olive oil}

Tocopherols are important components of the unsaponifiable fraction in vegetable oils. This family of compounds is particularly important in preventing lipid oxidation processes in olive oils (Woollard and Indyk, 2003). Contradictory results have been reported regarding the influence of heating on the tocopherol content (Yoshida et al., 1995; Yen, 1990; Lane et al., 1997; Kim et al., 2002). We observed that the content of $\alpha$-tocopherol in olive oil decreased after roasting. It was $93.7 \pm 4 \mathrm{mg} / \mathrm{kg}$ in olive oil from unroasted fruits, whereas the content of $\alpha$-tocopherol for AO was $91.7 \pm 5 \mathrm{mg} / \mathrm{kg}$. Conversely, an increase of $\gamma$-tocopherol was observed (from 2 to $4 \%$ ). However, there were no significant differences in the contents of $\delta$-tocopherol. We also observed the absence of the $\beta$-tocopherol in both oils.

Changes in the concentration of chlorophylls and carotenes in the olive oil samples during roasting for $12 \mathrm{~h}$ are shown in Table 4. The concentration of chlorophylls increased from $9.1 \pm 2.3 \mathrm{mg} / \mathrm{kg}$ to $24.1 \pm 2.4 \mathrm{mg} / \mathrm{kg}$, whereas that of carotenes
Table 5. Polycyclic aromatic hydrocarbons (PAH) in olive oils (ppb).

\begin{tabular}{llc}
\hline & Olive oil & \multicolumn{1}{c}{ Alwana } \\
\hline B(a)A & $2.19 \pm 0.2$ & $31.3 \pm 0.3$ \\
Chrysene & $2.44 \pm 0.1$ & $14.85 \pm 0.4$ \\
B(b)F & $0.26 \pm 0.02$ & $2.92 \pm 0.1$ \\
B(a)P & $0.51 \pm 0.01$ & $1.59 \pm 0.02$ \\
Sum (ppb) & 5.40 & 50.66
\end{tabular}

All values are the mean of three replicates \pm standard deviation of the mean.

increased from $4.96 \pm 0.1$ to $7.11 \pm 0.2 \mathrm{mg} / \mathrm{kg}$ during the roasting process. During the extraction process, a proportion of the native chlorophylls is transformed into pheophytins when the central $\mathrm{Mg} 2+$ ion of the porphyrin ring is substituted by $\mathrm{H}+$. This reaction is visually very striking, because it directly affects the chromophore group of the chlorophyll, and the color changes from bright green to olive brown. Only a part of the original chlorophyll content of the fruit remains intact in the oil. In the carotenoid fraction, the acidity of the medium causes isomerization of the 5,6-epoxide groups to 5,8furanoids.

\subsection{Effect of roasting of olive fruits on polycyclic aromatic hydrocarbons (PAH) of olive oil}

PAH belong to a large class of organic compounds originated from incomplete combustion of organic matter, known or suspected to be carcinogenic and genotoxic to mammals. Benzo[a]pyrene is the most studied PAH and is used as a marker. The main sources of PAH in foods are the environmental contamination and the food processing (such as smoke curing, cooking over charcoal and roasting). Results for Alwana oil samples are presented in Table 5. Similarly as for Rodriguez-Acuña et al. (2008), BaA, Chrysene, BaP and BbF were the main PAHs, with concentrations ranging from $2.19 \pm 0.2$ to $31.3 \pm 0.3,2.44 \pm 0.1$ to $14.85 \pm 0.4,0.51 \pm 0.01$ to $1.59 \pm 0.02$ and $0.26 \pm 0.02$ to $2.92 \pm 0.1 \mu \mathrm{g} / \mathrm{L}$, respectively. For all compounds, an increase was noticeable for olive oil from roasted fruits. The highest increase was found for benz[a] anthracene, and the lowest was for $\mathrm{BaP}$.

$\mathrm{B}[\mathrm{a}] \mathrm{P}$ frequently occurs in roasted material. In a previous and preliminary study performed at a roasting temperature of $100^{\circ} \mathrm{C}$, it was demonstrated that roasting of argan kernels did not induce the formation of $\mathrm{B}[\mathrm{a}] \mathrm{P}$ (Harhar et al., 2011). Nevertheless, we took advantage of this study to reinvestigate $\mathrm{B}[\mathrm{a}] \mathrm{P}$ content because of the known toxicity of this compound (Powrie et al., 1986).

The EU has set a maximum level of $2.0 \mu \mathrm{g} / \mathrm{kg}$ for BaP in oils and fats intended for direct consumption or used as an ingredient in foods (European Commission, 2005, 2006). Prior to that, some countries (Spain, Italy, Portugal and Greece) have established limits for the concentration of the following eight heavy PAH: BaA, BeP, BbF, BkF, BaP, DhA, BgP, IcP. The values established were a maximum limit of $2 \mu \mathrm{g} / \mathrm{kg}$ for each single PAH and $5 \mu \mathrm{g} / \mathrm{kg}$ for the sum of the referred eight heavy PAH (Teixeira et al., 2007). Some organizations establish their 
own recommendations, such as the German Society for Fat Science (GSFS), who suggested that the total PAH level in edible oils should not surpass $25 \mu \mathrm{g} / \mathrm{kg}$ and heavy PAH should be below $5 \mu \mathrm{g} / \mathrm{kg}$ (Cejpek et al., 1998). For our result, we found that the sum surpass $50 \mu \mathrm{g} / \mathrm{kg}$.

\section{Conclusions}

In conclusion, PAHs increase significantly during roasting. B (a)A and Chrysene were the major PAHs in the olive oil samples analyzed in this study. Even though they were present in olive oil from unroasted fruits, their content increased during the roasting process under elevated temperatures (about $130^{\circ} \mathrm{C}$ ), up to $15-$ $50 \mu \mathrm{g} / \mathrm{kg}$. Strong roasting conditions led to significant levels of chrysene and benzo[a]anthracene (near $13 \mu \mathrm{g} / \mathrm{kg}$ ), whereas low levels of anthracene, benzo[b]fluoranthene, and benzo[a]pyrene were also noted in those samples.

The avoidance of these contaminants in the diet is highly desirable and special attention must be given to the intake of roasted foods since considerable amount of PAHs can be ingested in a single meal.

Acknowledgments. We thank The Ibn ZOHR Association for Scientific Research and Sustainable Development for their interest in this work and financial support.

\section{References}

Allalout A, Krichene D, Methenni K, et al. 2009. Characterization of virgin olive oil from super intensive Spanish and Greek varieties grown in Northern Tunisia. Sci Hortic 120: 77-83.

Anjum F, Anwar F, Jamil A, Iqbal M. 2006. Microwave roasting effects on the physico-chemical composition and oxidative stability of sunflower oil. J Am Oil Chem Soc 83: 777-784.

Cejpek K, Hajslova J, Kocourek V, Tomaniova M, Cmolik J. 1998. Changes in PAH levels during production of rapeseed oil. Food Addit Contam 15: 563-574.

Coi/T.15/Nc n ${ }^{\text {3 } 3 / R e ́ v . ~ 7 . ~ 2013 . ~ N o r m e ~ c o m m e r c i a l e ~ a p p l i c a b l e ~ a u x ~}$ huiles d'olive et aux huiles de grignon d'olive.

Cossignani L, Simontti MS, Neri A, Damiani P. 1998. Changes in olive oil composition due to microwave heating. J Am Oil Chem Soc 75: 931-937.

Djebali HM, Krichene D, Ouni Y, et al. 2012. Chemical profiles of five minor olive oil varieties grown in central Tunisia. J Food Compost Anal 27: 109-119.

El Alaoui N. 2007. Une presse à huile au Maroc. Tech Cult 48-49: 189-218.

European Commission Regulation Eec/2568/91. 2003. Regulation $2568 / 91$ on the characteristics of olive oil and olive-residue oil and on relevant methods of analysis and later amendments. Annex II: determination of acidity value. Annex III: determination of peroxide index. Annex ix: spectrophotometric test of uv absorption. Off J Eur Communities 1248: 1-109.

European Commission. 2005. Commission Regulation (Ec) No. 208/ 2005 amending Regulation (Ec) No.466/2001 as regards Polycyclic Aromatic Hydrocarbons. Off J Eur Union L34/3-5.

European Comission. 2006. Commission Regulation (Ec) No. 1881/ 2006. Setting maximum levels of certain contaminants in foodstuffs. Off J Eur Union L364/5-24.

Fukuda Y. 1990. Food chemical studies on the antioxidants in sesame seed, Nippon Shokuhin Kogyo Gakkaishi. J Jpn Soc Food Sci 37: 484-492.
Gharby S, Harhar H, El Monfalouti H, et al. 2011. Chemical and oxidative properties of olive and argan oils sold on the Moroccan market. A comparative study. Med J Nutrition Metab 44: 1-8.

Gharby S, Harhar H, Guillaume D, Haddad A, Charrouf Z. 2012. The origin of virgin argan oil's high oxidative stability unraveled. Nat Prod Com 7: 1-3.

Gharby S, Harhar H, Kartah B, Chafchaouni I, Sibawayh Z Charrouf. 2013. Chemical characterization and oxidative stability of two monovarietal virgin olive oils (Moroccan picholine and arbequina) grown in Morocco. J Mater Environ Sci 4(6): 935-942.

Gharby S, Harhar H, Mamouni R, Matthäus B, Ait Addi E, Charrouf Z. 2016. Chemical characterization and kinetic parameter determination under Rancimat test conditions of four monovarietal virgin olive oils grown in Morocco. OCL 23 (4): A401.

Giocametti J, Milin C. 2001. Composition and qualitative characteristics of virgin olive oils produced in Northern Adriatic Region, Republic of Croatia. Grasas Y Aceites 52: 397-402.

Gordon Mh, Magos P. 1983. The effects of sterols on the oxidation of edible oils. Food Chem 10: 141-147.

Gutierrez F, Varona I, Albi MA. 2000. Relation of acidity and sensory quality with sterol content of olive oil from stored fruit. J Agric Food Chem 48(4): 1106-1110.

Harhar H, Gharby S, Kartah B, El Monfalouti H, Guillaume D, Charrouf Z. 2011. influence of argan kernel roasting-time on virgin argan oil composition and oxidative stability. Plant Foods Hum Nutr 66: 163-168.

Kim I-H, Kim C-J, You J-M, et al. 2002. Effect of roasting temperature and time on the chemical composition of rice germ oil. J Amer Oil Chem Soc 79: 413-418.

Lane RH, Quereshi AA, Salser WA. 1997. Tocotrienols and tocotrienol-like compounds and methods for their use. Us Patent, 5,591,772.

Lee YC, Oh SW, Chang J, Kim IH. 2004. Chemical composition and oxidative stability of safflower oil prepared from safllower seed roasted with different temperatures. Food Chem 84: 1-6.

Mataix J, Battino M, Ramirez-Tortosa MC, Bertoli E, Quiles J. 2008. Virgin olive oil: a key healthy component of the Mediterranean diet. Mediterr J Nutr Metab 1: 69-75.

Megahad MG. 2001. Microwave roasting of peanuts: effects on oil characteristics and composition. Nahrung 45: 255-257.

Mínguez-Mosquera MI, Rejano-Navarro L, Gandul-Rojas B, Sánchez-Gómez AH, Garrido-Fernández J. 1991. Color-pigment correlation in virgin olive oil. Ibid 69: 332-336.

Morales FJ, Babbel M-B. 2002. Melanoidins exert a weak antiradical activity in watery fluids. J Agric Food Chem 50: 4657-4661.

Moreau RA, Whitakerb BD, Hicksa KB. 2002. Phytosterols, phytostanols, and their conjugates in foods: structural diversity, quantitative analysis, and health-promoting uses. Prog Lipid Res 41: 457-500.

Powrie Wd, Wu Ch, Molund Vp. 1986. Browning reactions systems as sources of mutagens and antimutagens. Environ Health Perspect 67: 47-54.

Régis J, Joffre F, Fine F. 2016. Impact de la trituration et du raffinage sur la teneur en micronutriments des huiles végétales de colza, soja et tournesol. OCL 23(3): D302.

Rodriguez-Acuña R, Perez-Camino MC, Cert A, Moreda W. 2008. Sources of contamination by polycyclic aromatic hydrocarbons in Spanish virgin olive oils. Food Addit Contam 25: 115-122.

Stark AH, Madar Z. 2002. Olive oil as a functional food: epidemiology and nutritional approaches. Nutr Rev 60: 170-176. 
Teixeira VH, Casal S, Oliveira MBPP. 2007. PAHs content in sunflower, soybean and virgin olive oils: Evaluation in commercial samples and during refining process. Food Chem 104: 106-112.

Vieira TM, Regitano D'arce MAB. 2002. Uv spectrophoto-metric evaluation of corn oil oxidative stability during microwave heating and oven test. Nahrung 46: 279-282.

Woollard DC, Indyk HE. 2003. Tocopherols. In encyclopedia of food science and nutrition. London: Academic Press, pp. 5789-5796.

Yen GC. 1990. Influence of seed roasting process on the changes in composition and quality of sesame (Sesame Indicum) oil. J Sci Food Agr 50: 563-570.
Yoshida H, Shigezaki J, Takagi S, Kojimoto G. 1995, Variations in the composition of various acyl lipids, tocopherols and lignans in sesame seed oils roasted in a microwave oven. J Sci Food Agric 68: 407-415.

Yoshida H, Hirakawa Y, Abe S, Mizushina Y. 2002. The contents of tocopherols and oxidative quality of oils prepared from sunflower (Helianthus Annuus L.) seeds roasted in a microwave oven. Eur J Lipid Sci Technol 104: 116-122.

Yoshida H, Hirakawa Y, Tomiyama Y, Miz Y. 2003. Effect of microwave treatment on the oxidative stability of peanut (Arachis Hypogeae) oils and the molecular species of their triacylglycerols. Eur J Lipid Sci Technol 105: 351-358.

Cite this article as: Gharby S, Harhar H, Farssi M, Ait Taleb A, Guillaume D, Laknifli A. 2018. Influence of roasting olive fruit on the chemical composition and polycyclic aromatic hydrocarbon content of olive oil. OCL 25(3): A303. 